\title{
Toward a Dramatic World: The Latest Resurgence of Drama and Speculative Materialism
}

\section{Naruhiko Mikado}

Associate, Editorial Board of Osaka Literary Review, Osaka University, Suita, Japan.

Mail Id: track.and.basketball@gmail.com

\begin{abstract}
This essay has two aims: it tries, first, to demonstrate that there is an unignorable correlative relationship between the current resurgence in the popularity of stage plays and the meteoric rise of Speculative Materialism, a philosophical school led by Quentin Meillassoux, and, second, to elicit a useful insight for contemporary people who live in an era when the postmodern relativism has run into a snag. Concretely, the first part shows that any drama enjoins its audience to assent to the 'dramatic premise', which is a set of implicit presuppositions. The second part analyzes the fundamental tenets of Speculative Materialism, and points out that there is a curious similitude between the 'dramatic premise' and the perspective which the new philosophy urges us to adopt. The last part concludes the discussion by proposing a possible worldview that can be drawn from the investigation into the similarity between the outwardly irrelevant items.
\end{abstract}

Keywords: Drama, Philosophy, Speculative Materialism, Interdisciplinary Studies

\section{Introduction}

Insofar as one can judge by recent accounts in the media, it would not be amiss to presume that drama is still a powerful art form and has now been gaining more popularity in the four quarters of the globe. For example, one can adduce the fact that diverse Shakespearean plays are daily staged in countries well beyond their homeland, i.e. "all over the world" (Taylor and Bourus 3), while another may refer to "a remarkable resurgence of stage plays in China" (Cai 77), or point out that a fair number of drama festivals have been newly launched in Japan lately.

Meanwhile, if one ponders on the reality that there are many other formats which can render a fictional story in a more believable and impressive fashion, it seems a little, if not much, odd that the venerable medium of aesthetic expression has not been consigned to a mediocre position heretofore. 
But, when taking a broader perspective, one would soon discover that the continuous demand in stage plays should not be assessed as an independent phenomenon unrelated to other cultural and intellectual trends. Actually, the resurgence of the theater is presumably relevant, or at least correlative to the revolutionary advent of Speculative Materialism, a philosophical school led by the contemporary French thinker Quentin Meillassoux.

Below this paper attempts, first, to demonstrate the reason why the two items that appear remote from one another could be considered mutually corollary, and second, to elicit contemporaneous insight from the similitude between the philosophy and the 'dramatic premise'.

\section{Drama Grounded in the 'Dramatic Premise'}

Drama is, as Lockert observed, "the most enduring of literary forms" (509), and there have been innumerable essays in which individuals propounded their theories about the art. For instance, one can cite Aristotle's Poetics as one of the classical texts that handled drama; Tertullian is another ancient figure who advanced an influential discussion thereof. Amongst such works, articles to which we ought to pay eager attention are the one that was written by Alladyce Nicole in 1935 and the thesis of Julia Eaton, because their arguments, produced in the times when visually recorded mediums were rapidly acquiring vogue, looks to have captured essential properties of drama as well as substantial differences between novel visual arts and the stage.

By comparing features constituting the cinema and drama, the essay of the former explains that, when watching a film, people "carry into the picture-house prejudices deeply ingrained in our beings" (Nicole 75); put differently, the spectators of a movie forget, or at least tend to forget that they are viewing a succession of 'fictional' incidents and assume the scenes unfolding before their eyes to be 'real'. Then, except for some metafictional productions, a work employing modern techniques like videography and cinematography usually seeks to efface the border between fiction and reality.

In contrast, a stage play ordinarily aims to present a series of events "in bold theatric terms" (Nicole 74; italics added). Fleshing out the case of Nicole, Eaton brings forward the argument that a theatrical piece categorically enjoins its audience to construe the occasions happening on the stage with "a set of implicit covenants which are not necessarily logical" (5). To express it more concretely, if one wants to appreciate a drama, he must agree to a number of presuppositions which are comparable to rituals - namely, conventions which are accepted "because they have been accepted" (Eaton 7).

True, people interpreting any work of art have to take a certain number of such preconditions for granted; nevertheless, they are commonly deemed as negative evidence of inability to represent 
reality as it is. Considering that the era during which drama had been the sole form which could present a story with actions of humans ended long ago, that the limitations of other mediums have been overcome one after another, and that the mimetic competence of TV and cinema today is much greater than that of drama, one would estimate it to be curious that the age-old modus which has more restraints and requires its audience to comply with many tacit protocols is now recovering the status. One prominent contemporary dramatist even professed that his work is "a ritual enactment" (Akhtar 10; italics added).

So why do people continue to embrace such an art-form whose representational capacity seems severely bound by a network of 'ritual' codes, or, more simply, the 'dramatic premise'? If one examines only matters relevant to drama, he won't solve the question. This is, as the following sections will show, an issue that should be assessed with a more extensive outlook; philosophy is probably one of the valuable lenses to investigate it.

\section{Speculative Materialism: The World is 'Factual'}

Incidentally, philosophy is, in general, held to be a detached intellectual activity that has little relevance to practical affairs of the real world, and philosophers are often counted as weird fellows always pondering over speculative, esoteric conceptions. Certainly, these censures have some validity; yet, as long as it is conducted by 'live' humans, philosophical thoughts are essentially entwined with actual businesses of our societies, as Hegel once judiciously defined philosophy as "its own age apprehended in thought" (12; translation mine). In this sense, one can consider a predominant philosophical school to be reflective of the zeitgeist wherein it is produced. Additionally, philosophers are adept at abstracting and verbalizing what people vaguely intuit, as to which Merleau-Ponty once passed an incisive remark: "true philosophy consists in relearning to look at the world" (xxiii). Therefore, reviewing a leading philosophical thought enables one to gain a more accurate understanding of what people around him instinctively think and to analyze a cultural phenomenon from a bird's-eye standpoint.

Hence this section dissects Meillassoux's Speculative Materialism since its rise has largely paralleled the rejuvenation of the vogue of stage plays. Being one of the sects of the philosophical movement Speculative Realism, it has made a considerable impact upon miscellaneous fields other than philosophy since Meillassoux revealed it in his After Finitude. One of the most outstanding hallmarks of the book is that therein the philosopher quite persuasively disproves the 'principle of sufficient reason' which almost every modern person has taken as a given, nearly apriori law, and, replacing the old principle with "the principle of unreason", which he pithily names "facticity", contends that we should posit that the world has neither reason nor purpose; in other words, the existence of the world is merely "contingent" and "factual", and thus has no absolute, God-like truth behind or underneath it (Meillassoux 50-81). 
Deriving inspiration from the argument of Meillassoux and perceptively pointing out that Meillassoux didn't sufficiently discuss how one should see discrete things and specific phenomena in this contingent world defined by the principle of unreason, Masaya Chiba, a distinguished Japanese scholar, recently advanced a theory about how we should look upon them within the framework. First outlining his idea in figurative language, observing: "the unreason of the whole world, as it were, 'echoes' in every part of the world", Chiba, invoking Pierre Legendre's 'Dogmatic Anthropology', puts forth an interesting averment: "the world is fabricated as a system of rituals which assume their form just because as they do"; and the expression 'rituals' encompasses objects of any ontological level. (Chiba 58-60; italics added).

One should not overlook the intriguing parallel between the 'dramatic premise' to which the audience of a drama must assent and the perspective which Speculative Materialism urges us to adopt: both of them, like a ritual, prompt us to accept things and occurrences, whether they be on stage or in the tangible world, just as they are, i.e. as facts. Allowing for the fact that both drama and Speculative Materialism are seeing their rise concurrently right now, it would be improper of us to dismiss the correlation as a sheer nonsense; rather, we should regard this coincidence as reflecting an ongoing change in the reasoning framework of our contemporaries, who may begin noticing that poststructuralist 'relativism' has, though having disseminated the invaluable notion of 'diversity', struck a huge snag.

\section{Conclusion: Toward a 'Dramatic' Worldview}

Of course, one might deem it impetuous to link the two subjects only because they are becoming prominent simultaneously, and it isn't unlikely that the boom of one or both will soon wither; notwithstanding, it would be allowed to seek and experimentally tender a proposition to broaden our horizons from the view that existing things are 'factual', as opposed to necessary. It seems that the similar orientation between Speculative Materialism and the 'dramatic premise' can suggest a radical but effective way to coexist with other beings which is different from that which postmodernist relativism had hitherto proffered. Below is a sketchy proposal thereof.

Relativism still retained the shadow of the final, unfathomable 'truth' whence every interpretation is made; therefore, within the mindset, when one finds oneself at odds with someone over an issue, he would assume that either of their opinions/interpretations of the matter must be wrong. In lieu, the 'dramatic premise' and Speculative Materialism recommend us to postulate that what each of us experiences are never subjective constructions, but 'facts' by themselves, which means that each individual lives in one's own system of facts; to put it radically, every being lives in a different universe. Although one may denounce such an idea as hopeless nihilism, it is not. It makes us conscious that every one of us has no legitimate right to obtrude one's norms; instead, one ought to 'invite' another to visit one's world. It will capacitate us to embrace others despite 
that they live in a discrete world, and to welcome the surprise which they may spring. Quotidian as this conclusion might sound, the author of this paper here wants to 'invite' you readers to reconsider the world and diverse things in it with the 'dramatic' worldview.

\section{Acknowledgements}

Here I express my deepest gratitude to my parents, mentors, and my beloved for their unstinting support.

\section{References}

Akhtar, Ayad. Junk: A Play. New York: Back Bay Books, 2017. Print.

Cai, Shenshen. "Meng Jinghui and his Contemporary Avant-Garde Drama." New Zealand Journal of Asian Studies 16.1 (2014): 75-92. Print.

Eaton, Julia. "Character as the Basis of Play Construction." MA thesis. Cornell University, 1937. Print.

Hegel, Georg Wilhelm Friedrich. Grundlinien der Philosophie des Rechts. Berlin: Ullstein, 1972. Print.

Lockert, Lacy. Studies in French-Classical Tragedy. Nashville: Vanderbilt UP, 1958. Print.

Masaya, Chiba. “The Unreason or Rituality of the World." Comparative Civilization 32 (2016): 57-61. Print.

Meillassoux, Quentin. After Finitude. New York: Continuum, 2008. Print.

Merleau-Ponty, Maurice. Phenomenology of Perception. New York: Routledge, 2006. Print.

Taylor, Gary, and Terri Bourus. "Why Read Shakespeare's Complete Works?” The New Oxford Shakespeare: The Complete Works. Eds. Gary Taylor and Terri Bourus. Oxford: Oxford UP, 2017, 35-44. Print.

Naruhiko Mikado has completed his post-graduation from Osaka University, Japan. Presently, he is working as an Associate, Editorial Board of Osaka Literary Review, Osaka University, Suita, Japan. While majoring in American Literature, especially critical analysis of the works of Washington Irving, he has interest in diverse fields such as philosophy, media studies, and narratology other than literary criticism. 